\title{
Association of Escherichia coli 0157:H7 with necrotizing enterocolitis in a full-term infant
}

\author{
Yigit S. Guner · Ajay Malhotra $\cdot$ Henri R. Ford \\ James E. Stein · Lisa K. Kelly
}

Accepted: 31 March 2009/Published online: 26 April 2009

(C) The Author(s) 2009. This article is published with open access at Springerlink.com

\begin{abstract}
Necrotizing enterocolitis (NEC) is the most common gastrointestinal emergency of the neonate. NEC is predominantly seen in premature infants; however, in rare instances it can affect full-term infants as well. Although the pathogenesis of NEC remains elusive, it is well established that bacterial colonization is required for development of this disease. In this report, we present a case of a full-term infant, who developed a very aggressive form of NEC and was found to have Escherichia coli (E. coli) $\mathrm{O} 157: \mathrm{H} 7$ both in stool and blood cultures. Unfortunately, despite aggressive surgical and intensive care management, this infant suffered pan-intestinal necrosis and expired. We were not able to establish the
\end{abstract}

Y. S. Guner · H. R. Ford · J. E. Stein

Department of Pediatric Surgery,

Childrens Hospital Los Angeles, Los Angeles, CA, USA

e-mail: yguner@chla.usc.edu

H. R. Ford

e-mail: hford@chla.usc.edu

Y. S. Guner

Department of Surgery,

University of California Davis Medical Center,

Sacramento, CA, USA

A. Malhotra $\cdot$ H. R. Ford · J. E. Stein

Keck School of Medicine, University of Southern California,

Los Angeles, CA, USA

L. K. Kelly $(\square)$

Department of Pediatrics, Keck School of Medicine,

Center for Fetal and Newborn Medicine,

Childrens Hospital Los Angeles,

4650 Sunset Blvd, MS \#31, Los Angeles,

CA 90027, USA

e-mail: 1kelly@chla.usc.edu route of transmission. To our knowledge, this is the first report of the association of E. coli O157:H7 with NEC.

Keywords Neonate $\cdot$ NEC $\cdot$ Mortality $\cdot$ HUS .

Bacteria

\section{Introduction}

Necrotizing enterocolitis (NEC) is the most common gastrointestinal emergency of the newborn infant and a leading cause of mortality in the neonatal period [1,2]. Given the increase in low birth weight deliveries and recent advances in neonatal intensive care, a growing percentage of newborn infants are at risk of developing NEC. Unfortunately, the mortality rate associated with NEC has not changed in the last two decades [3, 4]. Currently, evidence suggests that NEC is, at least in part, due to an inappropriate inflammatory response of the immature gut to various perinatal insults [2]. The inciting event is thought to be local mucosal injury in a susceptible host, leading to bacterial translocation across the gut barrier and activation of various inflammatory mechanisms [5]. As a result of a disarray of inflammatory signaling, high levels of cytokines, chemokines, and free radicals are released, propagating further tissue injury and, if not corrected, sepsis and shock [5]. The presence of bacteria within the intestinal lumen is integral to the pathogenesis of NEC $[5,6]$. In this report, we present a case of NEC occurring in a 4-day-old full-term male neonate colonized with $E$. coli O157:H7. Despite the overwhelming evidence regarding the bacterial involvement in the pathogenesis of NEC [6,7], to our knowledge, there have been no previous reports of O157:H7 colonization of a neonate with a correlative finding of NEC, as described in this case. 


\section{Case presentation}

The patient described herein was a full-term, borderline small for gestational age $2.5 \mathrm{~kg}$ male infant, born vaginally after an uncomplicated pregnancy and delivery. He was discharged home on postnatal day \#2 on term formula due to difficulty in establishing breast feeding in the hospital. The family reported occasional bouts of emesis prior to discharge from the newborn nursery. Over the next $24 \mathrm{~h}$ the baby became fussier and began to vomit after every feeding with concomitant bloody stools. On postnatal day \#4, the parents brought the infant to the emergency department (ED).

Upon presentation, the infant was lethargic, febrile $\left(39.4^{\circ} \mathrm{C}\right)$, tachycardic $(190-200 \mathrm{bpm})$, and acidotic with a base deficit of 13. Abdominal imaging demonstrated free air and pneumatosis intestinalis (Fig. 1). After aggressive fluid resuscitation and administration of broad-spectrum antibiotics, we performed an exploratory laparotomy. The procedure took $40 \mathrm{~min}$. There was gross fecal contamination throughout the peritoneal cavity resulting from two perforations in the distal ileum. These were resected along with $20 \mathrm{~cm}$ of intervening ileum and a proximal ileostomy and creation of Hartmann's pouch was performed. The patient was then transferred to the neonatal intensive care unit (NICU) where he was profoundly thrombocytopenic, acidotic ( $\mathrm{pH}$ 6.8-6.9, base deficit $>20$, lactate $>135$ ), and hypotensive with extremely poor capillary refill. Within the next $5 \mathrm{~h}$, the patient continued to deteriorate despite aggressive fluid resuscitation $(110 \mathrm{cc} / \mathrm{kg}$ of crystalloid $+100 \mathrm{cc} / \mathrm{kg}$ of blood products due to ongoing DIC in addition to maintenance fluid administration at $150 \mathrm{ml} / \mathrm{kg}$ per day). An echocardiogram revealed a patent ductus arteriosus (PDA) with bidirectional flow, pulmonary hypertension, and a patent foramen ovale (PFO). Because the patient remained in persistent septic shock, he was reexplored at the bedside $7 \mathrm{~h}$ after the initial operation. The remainder of the small bowel appeared to be hypo-perfused without any evidence of frank necrosis. The skin was temporarily closed with a plan for repeat exploration.

Over the next $48 \mathrm{~h}$, the patient remained hemodynamically labile and developed multi-organ dysfunction including the kidneys and liver. However, after ongoing intensive care management, the infant's hemodynamic status and lactic acidosis improved significantly over the next 2 days. At this time, re-exploration of the peritoneal cavity revealed progressive hypo-perfusion and pneumatosis involving the entire length of the small bowel and the majority of the large bowel. The family was counseled about the grim prognosis, but elected to continue with the ongoing aggressive care. Over the next $48 \mathrm{~h}$, the patient became anuric and required increasing ventilatory support. A bedside abdominal decompression was performed. The

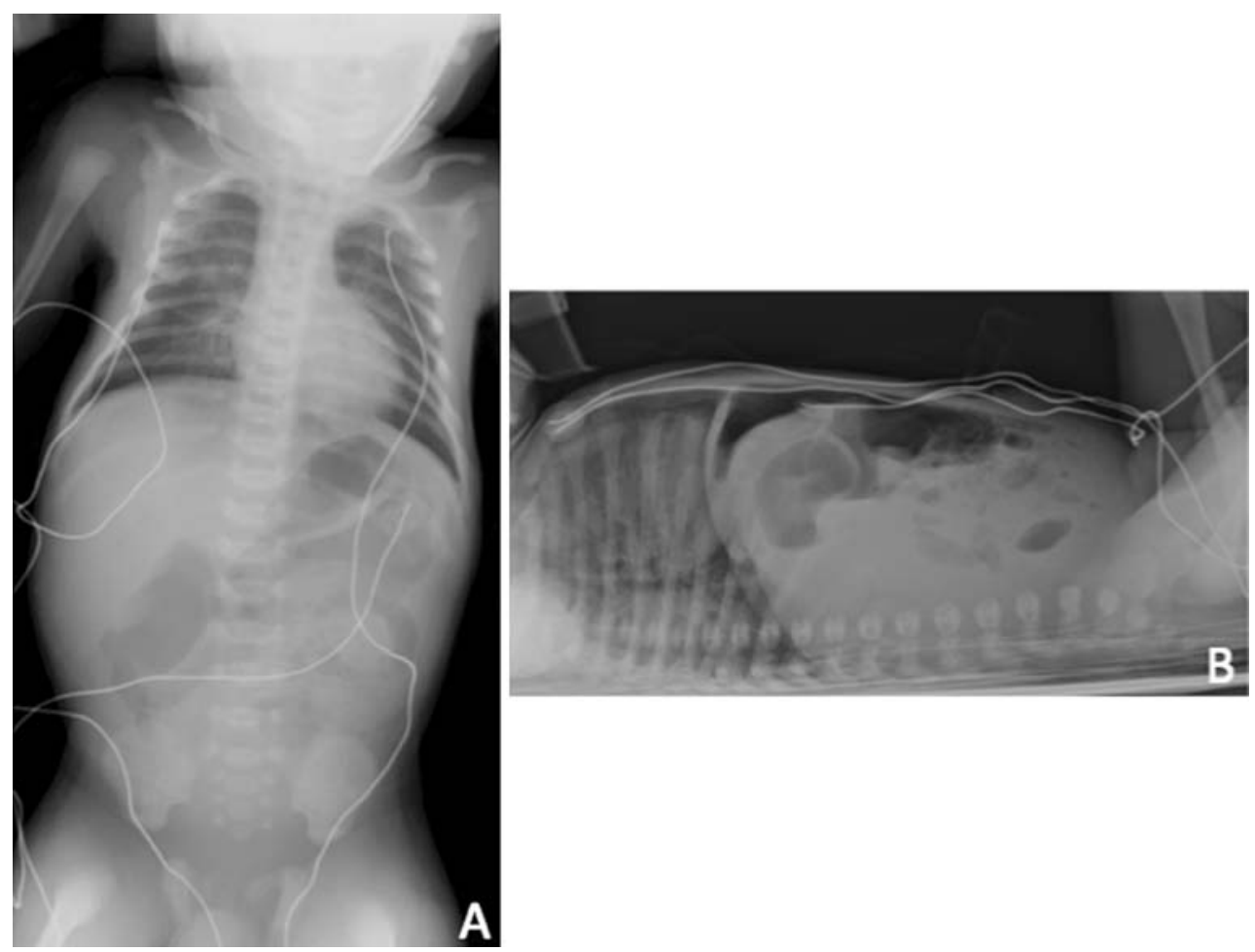

Fig. 1 Supine AP (a) and cross table lateral (b) demonstrate free air and pneumatosis intestinalis 

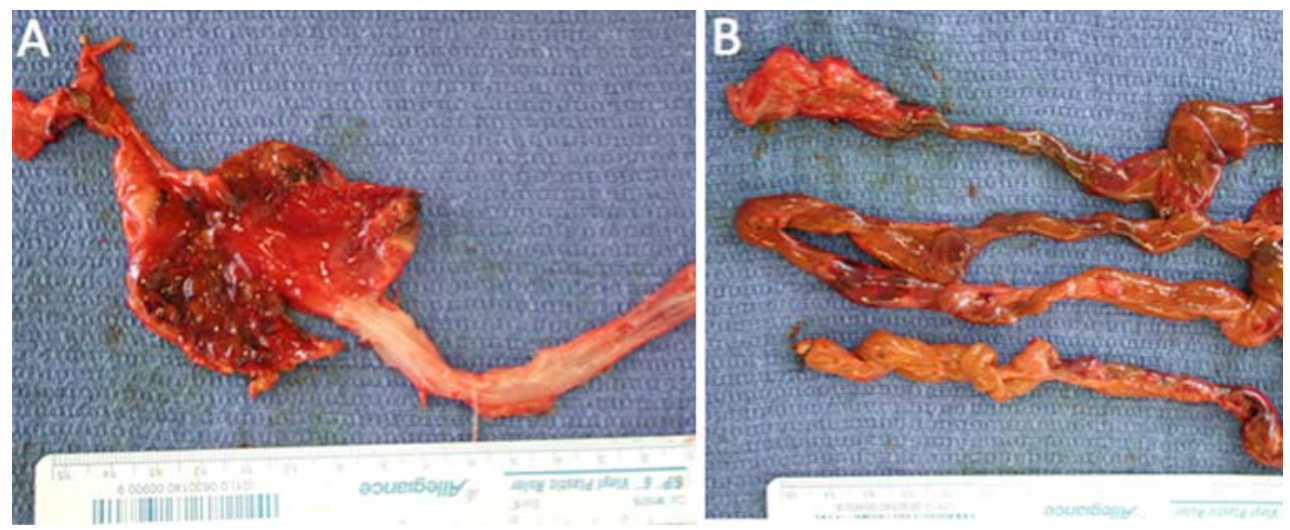

Fig. 2 a Stomach and esophagus: the stomach is necrotic, the esophagus is not affected. b The entire small bowel, which appears necrotic

entire small bowel, stomach and portions of large bowel appeared necrotic and hemorrhagic (Fig. 2). There was extensive pneumatosis and additional areas of perforation within the small bowel. The family was counseled about the baby's moribund state and agreed to accept natural death. The patient received comfort care for the next 24-48 $\mathrm{h}$ and then support was withdrawn. The infant expired shortly thereafter.

On the day of the patient's death, the admitting blood cultures were noted to be growing E. coli $\mathrm{O} 157: \mathrm{H} 7$, and stool cultures collected on presentation in the ED also grew E. coli $\mathrm{O} 157: \mathrm{H} 7$ strain. We were unable to determine whether anyone in the family had been exposed to this pathogen, but all family members tested negative for E. coli sero-group O157:H7. Unfortunately, the family had discarded the patient's formula; therefore we were unable to test it. The birth hospital was notified regarding these findings.

\section{Discussion}

Herein, we report the first association of E. coli serogroup O157:H7 with NEC. E. coli $\mathrm{O} 157: \mathrm{H} 7$ is an enterohemorrhagic strain most commonly associated with hemolytic uremic syndrome (HUS). Roughly $90 \%$ of the cases occur in children and the remainder in adults [8,9]. To our knowledge, there is only one previously reported case of neonatal HUS [10]. That infant, reported by Ulinski et al. [10], presented at 7 days of age with bloody diarrhea and vomiting and developed renal insufficiency, thrombocytopenia and hemolysis but not NEC. This neonate recovered after successful medical management [10]. Interestingly, the mother of that infant was found to have the O157:H7 strain in her stools; thus the authors concluded that the transmission was vertical (mother-to-child) [10], a clinical finding not previously described. Unfortunately, we were unable to establish the source or route of transmission in our patient.
The association between E. coli $\mathrm{O} 157: \mathrm{H} 7$ and NEC in a term infant underscores the importance of bacterial colonization in the pathogenesis of NEC. There is a growing body of evidence that suggests that early colonization of the newborn intestinal tract by Gram-negative organisms is integral to the development of NEC $[6,11]$. Neonates have a markedly different intestinal flora compared to adults which may influence the development of NEC. In the neonate, indigenous bacteria colonize the mucosal surfaces and the intestinal lumen in a typical pattern called succession [5]. The initial phase of succession lasts from birth to 2 weeks. During that period, Streptococci and coliforms predominate. Gram-positive, non-spore-forming anaerobes appear such as Bifidobacteria and Lactobacilli [12]. The latter phases of succession occur from the end of phase I to the consumption of solid food when Bacteroides progressively increase in number until the flora resembles that of adults [5]. The indigenous intestinal microflora, especially the anaerobes, normally restrict the number of coliforms to relatively low levels. However, in the environment of a NICU, especially without breast milk feeding, abnormal floral patterns can emerge [13]. Because there is a relative paucity of anaerobes during the initial phase of succession, pathogenic bacteria may be more likely to colonize the neonatal gut, and thus contribute to the pathogenesis of NEC, which typically develops during the first 2 weeks of life.

Although no one bacterial species fulfills all of Koch's postulates, some bacteria are frequently associated with NEC. The most commonly reported species associated with NEC are Enterobacteriaceae (Escherichia, Salmonella, Klebsiella, and Enterobacter species) [6, 11]. Among these Gram-negative organisms, Enterobacter sakazakii is the most commonly described single organism associated with NEC. Hunter et al. [11] recently demonstrated that feeding laboratory rats with formula contaminated with Enterobacter sakazakii can accelerate and intensify the development of intestinal injury in an experimental model of NEC. Thus, the data support the hypothesis that early 
Gram-negative colonization of the intestine aids in the development of NEC in a susceptible host.

The most commonly accepted risk factors for NEC are prematurity and formula feeding [2]. Roughly $90 \%$ of NEC cases occur in premature infants $[14,15]$. Nevertheless, the remaining $10 \%$ of NEC cases are seen in term infants [16], where NEC can occur spontaneously after birth. However, many of these term infants also have co-morbidities that predispose them to NEC, such as intrauterine growth retardation, gastroschisis, polycythemia, sepsis or cardiac defects that lead to low flow states $[17,18]$. In fact, recent reports of NEC in full-term infants list cardiac anomalies as the most commonly associated comorbidity $[17,18]$. One important difference between term and pre-term infants is the age at presentation with NEC, such that term infants present earlier after birth (in the first 3-5 days of life), where pre-term infants usually present within 2-3 weeks of life [19]. The early presentation pattern is also evident in the infant described in this report. One additional factor commonly associated with NEC in premature infants is the presence of a hemodynamically significant patent ductus arteriosus. Although causation has not been established, infants with PDA have an increased incidence of NEC [20-24].

The risk factors for NEC that were present in the term neonate in this report are formula feeding and the presence of PDA. It is unclear whether the PDA contributed to the development of NEC in this neonate, as the first echocardiogram was obtained following the patient's first operation when he was already in florid septic shock. Critical illness is known to contribute to the reopening of a functionally closed ductus arteriosus in term neonate during the first postnatal week.

In summary, we report the first association between E. coli serogroup 0157:H7 and NEC. This infection caused the rapid demise of an otherwise healthy full-term neonate despite aggressive medical and surgical treatment. Although we have not been able to determine the route of transmission, health care providers should be aware of this pathogen, as it may be responsible for similar unreported cases.

Open Access This article is distributed under the terms of the Creative Commons Attribution Noncommercial License which permits any noncommercial use, distribution, and reproduction in any medium, provided the original author(s) and source are credited.

\section{References}

1. Sankaran K, Puckett B, Lee DS et al (2004) Variations in incidence of necrotizing enterocolitis in Canadian neonatal intensive care units. J Pediatr Gastroenterol Nutr 39(4):366-372. doi:10.1097/00005176-200410000-00012

2. Guner YS, Chokshi N, Petrosyan M, Upperman JS, Ford HR, Grikscheit TC (2008) Necrotizing enterocolitis-bench to bedside: novel and emerging strategies. Semin Pediatr Surg 17(4):255-265. doi:10.1053/j.sempedsurg.2008.07.004

3. Guner YS, Friedlich P, Wee CP, Dorey F, Camerini V, Upperman JS (2009) State-based analysis of necrotizing enterocolitis outcomes. J Surg Res (in press). doi:10.1016/j.jss.2008.11.008

4. Holman RC, Stehr-Green JK, Zelasky MT (1989) Necrotizing enterocolitis mortality in the United States, 1979-85. Am J Public Health 79(8):987-989. doi:10.2105/AJPH.79.8.987

5. Hackam DJ, Upperman JS, Grishin A, Ford HR (2005) Disordered enterocyte signaling and intestinal barrier dysfunction in the pathogenesis of necrotizing enterocolitis. Semin Pediatr Surg 14(1):49-57. doi:10.1053/j.sempedsurg.2004.10.025

6. Hunter CJ, Upperman JS, Ford HR, Camerini V (2008) Understanding the susceptibility of the premature infant to necrotizing enterocolitis (NEC). Pediatr Res 63(2):117-123. doi:10.1203/ PDR.0b013e31815ed64c

7. Brook I (2008) Microbiology and management of neonatal necrotizing enterocolitis. Am J Perinatol 25(2):111-118. doi:10. 1055/s-2008-1040346

8. Fiorino EK, Raffaelli RM (2006) Hemolytic-uremic syndrome. Pediatr Rev 27(10):398-399. doi:10.1542/pir.27-10-398 discussion 9

9. Iijima K, Kamioka I, Nozu K (2008) Management of diarrheaassociated hemolytic uremic syndrome in children. Clin Exp Nephrol 12(1):16-19. doi:10.1007/s10157-007-0007-4

10. Ulinski T, Lervat C, Ranchin B, Gillet Y, Floret D, Cochat P (2005) Neonatal hemolytic uremic syndrome after mother-tochild transmission of Escherichia coli O157. Pediatr Nephrol 20(9):1334-1335. doi:10.1007/s00467-005-1871-3

11. Hunter CJ, Singamsetty VK, Chokshi NK et al (2008) Enterobacter sakazakii enhances epithelial cell injury by inducing apoptosis in a rat model of necrotizing enterocolitis. J Infect Dis 198(4):586-593. doi:10.1086/590186

12. Hentges DJ (1993) The anaerobic microflora of the human body. Clin Infect Dis 16(Suppl 4):S175-S180

13. Hunter CJ, Podd B, Ford HR, Camerini V (2008) Evidence vs experience in neonatal practices in necrotizing enterocolitis. J Perinatol 28(Suppl 1):S9-S13. doi:10.1038/jp.2008.43

14. Chandler JC, Hebra A (2000) Necrotizing enterocolitis in infants with very low birth weight. Semin Pediatr Surg 9(2):63-72

15. Koffeman GI, van Gemert WG, George EK, Veenendaal RA (2003) Classification, epidemiology and aetiology. Best Pract Res 17(6):879-893

16. Ng S (2001) Necrotizing enterocolitis in the full-term neonate. J Paediatr Child Health 37(1):1-4. doi:10.1046/j.1440-1754. 2001.00584.x

17. Lambert DK, Christensen RD, Henry E et al (2007) Necrotizing enterocolitis in term neonates: data from a multihospital health-care system. J Perinatol 27(7):437-443. doi:10.1038/sj.jp. 7211738

18. Maayan-Metzger A, Itzchak A, Mazkereth R, Kuint J (2004) Necrotizing enterocolitis in full-term infants: case-control study and review of the literature. J Perinatol 24(8):494-499. doi:10. 1038/sj.jp.7211135

19. Sharma R, Hudak ML, Tepas JJ 3rd et al (2006) Impact of gestational age on the clinical presentation and surgical outcome of necrotizing enterocolitis. J Perinatol 26(6):342-347. doi:10.1038/ sj.jp. 7211510

20. Sankaran K, Chien LY, Walker R, Seshia M, Ohlsson A (2002) Variations in mortality rates among Canadian neonatal intensive care units. CMAJ 166(2):173-178

21. Hermes-DeSantis ER, Clyman RI (2006) Patent ductus arteriosus: pathophysiology and management. J Perinatol 26(Suppl 1):S14S18. doi:10.1038/sj.jp.7211465 discussion S22-3

22. O'Donovan DJ, Baetiong A, Adams K et al (2003) Necrotizing enterocolitis and gastrointestinal complications after indomethacin 
therapy and surgical ligation in premature infants with patent ductus arteriosus. J Perinatol 23(4):286-290. doi:10.1038/sj.jp. 7210911

23. Grosfeld JL, Chaet M, Molinari F et al (1996) Increased risk of necrotizing enterocolitis in premature infants with patent ductus arteriosus treated with indomethacin. Ann Surg 224(3):350-355. doi:10.1097/00000658-199609000-00011; discussion 5-7
24. Dollberg S, Lusky A, Reichman B (2005) Patent ductus arteriosus, indomethacin and necrotizing enterocolitis in very low birth weight infants: a population-based study. J Pediatr Gastroenterol Nutr 40(2):184-188. doi:10.1097/00005176200502000-00019 